\title{
A framework to harness effective partnerships for the sustainable development goals
}

\author{
David Horan ${ }^{1}$ (1)
}

Received: 6 April 2021 / Accepted: 25 November 2021 / Published online: 4 January 2022

(c) The Author(s) 2022

\begin{abstract}
The sustainable development goals (SDGs) offer a broad, holistic framework of interdependent economic, social, and environmental objectives to enable integrated and collaborative approaches to their implementation. A key obstacle for operationalizing such an approach is knowing the right actors to engage on specific challenges. It is acknowledged that linkages across sectors, scales, and actors could provide an evidence base to assess and forge participation in multistakeholder partnerships for implementation. However, technical tools that could help to identify relevant actors and discussions of institutional arrangements to bring these actors on board are notably lacking in the extant literature. To support an evidence-based and systematic approach to coalition building that accounts for synergies and trade-offs across goals and targets, this paper proposes broadbased partnerships and a framework that lead actors can use to help harness collaborative SDG implementation: (1) define the partnership's scope, (2) identify the main interlinkages, (3) assign responsibilities, (4) select the best available indicators, (5) assess the challenges, and (6) forge a broad-based partnership. After describing key decisions at each step, the article discusses applications of the proposed analytic partnership-building framework to problems that warrant the approach at global, regional, and national levels covering issues such as policy coordination across line ministries, global partnerships for SDG13 implementation in SIDS, energy compacts for SDG7 implementation, and integrated multilateral responses to crises.
\end{abstract}

Keywords Sustainable development goals (SDGs) · SDG implementation · Multistakeholder partnerships · Interlinkages · Actors' responsibilities · Dashboards of indicators

\section{SDG implementation and partnerships}

The 2030 Agenda with its 17 Goals, 169 targets and 232 indicators covers a wide range of global challenges that all actors at all levels can align with up to 2030 (United Nations 2015). With just 9 years left and no country currently on track to achieve all 17 SDGs (SDSN 2020, 2021), the UN Secretary General has called for coalitions of leadership to harness more concerted action in the SDGs Decade of Action (Beisheim and Fritzsche 2021; United Nations

Handled by Lee Bosher, Loughborough University, United Kingdom.

David Horan

david.horan@ucd.ie

1 School of Politics and International Relations and UCD Geary Institute for Public Policy, University College Dublin, Dublin D04 V1W8, Ireland 2019a, 2021). One important challenge for implementation, however, concerns the integrated nature of the SDGs and the need to capitalize on synergies and manage trade-offs between goals and targets to ensure efficient and equitable implementation (Alcamo 2019; Nilsson et al. 2016). In addition, substantive progress will require transformative action which means moving beyond incremental policy changes and siloed actions to cross-sectoral policy mixes, joined up actions and portfolios of coordinated interventions (United Nations 2019a, b; OECD 2019; Sachs et al. 2019; IIASA 2018).

Since their inception, scholarship in sustainability science has documented the complex and integrated nature of the SDGs (Le Blanc 2015; Nilsson et al. 2016; Pradhan et al. 2017). Much of the focus has been on developing scientific tools to assist policy makers with identifying and assessing synergies and trade-offs for coherent planning and policies (Allen et al. 2021a, b). Less attention has been devoted to developing analytic frameworks and evidence-based tools 
aimed at enhancing collaborative approaches to integrated implementation. The 2030 Agenda places a strong emphasis on partnerships as an important instrument to harness means of implementation such as finance, technology, data, etc., (United Nations 2015). While it is recognized that linkages between SDGs can be used to identify relevant actors to engage in and enable better partnerships (Nilsson et al. 2016; Weitz et al. 2017; Stafford-Smith et al. 2016; Horan 2021, 2020a), little research has been devoted to translating such connections into types of partnerships that might help with integrated implementation.

Bridging research on SDG interlinkages and partnerships is crucial for developing a collaborative approach to implementation. Ever since the World Summit on Sustainable Development in 2002, the UN has recognized broad stakeholder participation in partnerships as an important way to balance the economic, social, and environmental dimensions of development (see Bali Guidelines, Dodds 2015). Despite the popularity and growth of multistakeholder partnerships for sustainable development in the last two decades, low participation from local and non-state actors, such as universities, businesses, small NGOs, local communities and grassroot organizations, has been a consistent finding across studies (Reinsberg and Westerwinter 2019; Pattberg et al. 2012; Andonova and Levy 2003). In addition, as the Partnerships for SDGs Action Platform indicates, partnerships tend to cluster their activities around specific goals and individual goal approaches remain prominent (Alcamo et al. 2020; Chan et al. 2020). Moreover, partnership building is complex and costly, and the inclusion of non-relevant actors can undermine the effective running of a partnership (Banerjee et al. 2020; Stibbe et al. 2020; Caplan 2013). These observations raise the question whether representation problems in partnerships could lead to effective outcomes that address synergies and trade-offs.

Partnerships can support implementation in multiple ways. First, they can help to bridge the "ambition gap", i.e., where national policies are lacking or insufficient (Widerberg and Stripple 2016; Lui et al. 2020; Chan et al. 2018). Second, partnerships can improve the design and implementation of interventions and ensure equitable development by including marginalized groups and grassroot organizations thereby mitigating unintended negative consequences and trade-offs (Hale 2004). Third, international partnerships involving transnational actors are a way to access means of implementation where domestic and government resources are inadequate (Africa CDC 2021; Westman and Broto 2018; United Nations 2015; Pattberg et al. 2012).

A key challenge for enabling effective partnerships is knowing the right set of stakeholders to engage on specific challenges. Generally, there is a lack of technical tools to systematically identify relevant partners for integrated implementation and institutional arrangements to bring these actors together. Drawing on recent research, this article presents an SDG interactions-based framework to help identify relevant actors to engage that can be used to harness more collaborative approaches to integrated implementation. The proposed framework is useful to (1) assess levels of participation in broad-based partnerships to support implementation, and (2) to identify missing partners, based on knowledge of SDG interlinkages and actors' alignment to the SDGs. By seeking to identify those actors important for managing synergies and trade-offs, the framework offers a lens through which to examine an important aspect of the political economy of SDG implementation.

While much research has focused on assessing interactions between SDGs (Nilsson et al. 2016, 2018; Zhou and Moinuddin 2017; Weitz et al. 2014), much less attention has been devoted to developing approaches that use interlinkages to foster effective partnerships (Breuer et al. 2019a, b; Nilsson and Weitz 2019; Horan 2021, 2020a). Specifically, the article will address how knowledge of SDG interlinkages can be translated into practical proposals useful for improving participation in partnerships. After describing key decisions at each step, the article applies the framework to four problems that warrant the approach at global, regional, and national levels covering issues such as policy coordination across line ministries for implementing SDG14, global partnerships for SDG13 implementation in small island developing states (SIDS), energy compacts for SDG7 implementation, and integrated multilateral responses to crises.

\section{Two different approaches to integration}

The governance literature on coordination identifies three dimensions along which engagement can be pursued: across sectors (water, food, energy), across scales (global, national, and subnational) and across actors (IGOs, government, business, academia, and civil society groups) (Breuer et al. 2019b; OECD 2016; Pisano et al. 2013; Jänicke 2006). This literature (which usually focuses on policy integration and consultation with stakeholders for planning and budgeting), distinguishes three types of integration: horizontal integration involving collaboration across policy sectors between government ministries; vertical integration involving interactions between different administrative decision-making levels; and multistakeholder engagement by government with non-state actors (Breuer et al. 2019b; Zusman and Amanuma 2018).

In policy debates and academic literature on SDG implementation, greatest attention has focused on horizontal integration, i.e., linkages across sectors and policy coordination across ministries (Allen et al. 2021a, b; Bennich et al. 2020; Breuer et al. 2019b). Much of the research seeks to identify and assess the many interlinkages between SDGs (Nilsson 
et al. 2016; Alcamo 2019) and policies and interventions for efficient and effective implementation (Alcamo et al. 2020). Calls to enhance cooperation and coordination between line ministries are common (Nilsson et al. 2016; Weitz et al. 2017).

Two broad approaches to horizontal integration are evident in the literature, both of which propose very different levels of cooperation because of the scope of linkages considered. First, whole of government (WoG) approaches, popular in the Voluntary National Reviews, call on policies to be agreed by all departments through for example inter-departmental working groups (United Nations 2019a, b; Kindornay 2019; Glass and Newig 2019). Alternatively, nexus approaches, widely popular in quantitative modeling and long-term planning, focus instead on discussing policies in a small number of highly interlinked areas such as water, energy and food combined (Weitz et al. 2017). Whereas the WoG approach advocates cooperation among all departments potentially considering all possible linkages, the nexus approach focuses on collaborations usually among 2-3 departments and considers a much smaller range of linkages (Weitz et al. 2014, 2017). In terms of harnessing efficient implementation, neither of these recommendations is satisfactory. On the one hand, the WoG approach arguably calls for too much cooperation in that not everything is connected to everything at least in a first-order sense. On the other hand, the nexus approach advocates too little cooperation in that clearly, there are linkages beyond the nexus which ought to be accounted for.

In contrast, the literature on sustainability partnerships focuses instead on participation across stakeholder groups (Pattberg et al. 2012). Here, multistakeholder partnerships refer to voluntary collaborations among multiple stakeholders from different segments of society-public, private, and civil society-aimed at achieving a sustainability goal (Pattberg et al. 2012; Huijstee et al. 2007). Overall, the literature is more concerned with the governance implications of partnerships than their efficiency in supporting implementation (Huijstee et al. 2007). Broad stakeholder participation is generally viewed as desirable because of its role in enhancing the legitimacy of partnerships as an alternative governance arrangement (Backstrand 2006; Backstrand and Kuyper 2017). In particular, debates on partnership effectiveness typically focus on participation deficits (Chan and Mertz 2012), internal success conditions of partnerships (Beisheim and Simon 2018; Pattberg and Widerberg 2016), the role of orchestrators (Horan 2019a; Hale and Rogers 2014), and the degree of institutionalization of partnerships (Backstrand 2007).

Compared to the literature on SDG interactions, the partnership literature is relatively mute on participation across sectors ignoring potential synergies and tradeoffs that could arise across sectors (Nilsson et al. 2016; Stafford-Smith et al. 2016). Instead, the literature places a strong emphasis on the inclusion of all stakeholder groups in partnership. In practice though, full participation is rarely observed. Large $\mathrm{N}$ studies of partnerships tend to report low participation by actors from local and national levels, particularly in transnational partnerships which are often led by public actors such as UN agencies, intergovernmental organizations (IGOs), or national governments, either on their own or in some combination (Clough et al. 2018; Pattberg et al. 2012; Andonova and Levy 2003).

In summary, as noted in Table 1, whereas the focus in the literature on SDG implementation has been on identifying and assessing linkages across sectors, developing tools, and gathering evidence on SDG interactions for policies and planning, less attention has been devoted to how linkages can be used to foster multistakeholder approaches to collaborative implementation. On the other hand, linkages are barely mentioned in the partnership literature which focuses more on assessing participation of different stakeholder groups in partnerships, the extent to which partnerships address gaps in global governance, and the internal success conditions of partnerships.

Table 1 Approaches to integration

\begin{tabular}{|c|c|c|c|c|}
\hline Literatures & What & Focus & How & Why \\
\hline SDG implementation & SDGs/sectors & $\begin{array}{l}\text { National policy and } \\
\text { planning, horizontal } \\
\text { integration }\end{array}$ & Evidence-based decision-making tools & $\begin{array}{l}\text { More effective } \\
\text { national poli- } \\
\text { cies and imple- } \\
\text { mentation }\end{array}$ \\
\hline Sustainability partnerships & Stakeholders/actors & $\begin{array}{l}\text { Transnational partner- } \\
\text { ships, multistake- } \\
\text { holder participation }\end{array}$ & $\begin{array}{l}\text { Institutional arrangements, decision-mak- } \\
\text { ing processes, guidelines }\end{array}$ & $\begin{array}{l}\text { Improved } \\
\text { governance } \\
\text { effectiveness, } \\
\text { legitimacy }\end{array}$ \\
\hline
\end{tabular}

Adapted from Zusman and Amanuma (2018) 


\section{A framework for forging effective partnerships}

\section{Broad-based partnerships}

Drawing on the governance view of engagement, I define "broad-based partnership" (BBP) as a voluntary collaboration among multiple stakeholders from different sectors, scales, and stakeholder groups dedicated to implementing in an integrated way a sustainable development goal. First, this definition introduces to the partnership literature a new type of multistakeholder partnership that explicitly accounts for participation across sectors and scales. Second, by focusing the partnership's aim on integrated implementation, it proposes multistakeholder partnerships as a flexible governance arrangement to manage multiple synergies and trade-offs across goals and targets.

The notion of BBP espoused in this article focuses on a single "entry point" approach to implementation, namely a specific SDG goal, target, or synergy driver, and its main interlinkages with the other goals and targets. While the article side-steps the issue of how entry points are selected (see "Discussion"), this approach to integrative implementation, popular in the SDG interactions literature (cf. Alcamo 2019) and in practice (cf. One Health Initiative (World Bank 2018; One by One UHC Report 2020)), helps to keep the number of linkages at a manageable level (Alcamo et al. 2020), and by highlighting key interactions, it offers useful information to negotiate portfolios of coherent actions for integrated implementation (Alcamo 2019; Horan 2020a).

In particular, BBPs are to be thought of as a coalition of actors or "backbone partnership" for integrated implementation meaning the partnership acts like a springboard for joined up actions. The main output of a BBP should be a portfolio of actions, commitments, unilateral efforts, and partnerships that facilitates a collaborative approach to integrated implementation. Depending on the context, BBPs can be deployed at any scale-global, regional, national, subnational or local, and led by any actor or group of actors (government, international institution, university, corporate, local government, and communities).

Many examples of a "partnership of partnerships" based on single entry points exist at international, national, and more local levels. For instance, the Global Partnership for Sustainable Development Data (GPSDD) consists of 270 partners and has delivered over 70 partnerships (GPSDD 2020). The Scaling Up Nutrition alliance, Dutch Energy Agreement and the Hawaii Green Growth Platform also brought together diverse actors to incubate collaborative actions (Prescott and Stibbe 2020). Although rarely defined explicitly, BBPs are often alluded in contemporary debates on sustainable supply chains which calls for international cooperation and bilateral partnerships to ensure public and private actors work together to green each point of the supply chain (SDSN 2019; van Hille et al. 2020). However, these and other such partnerships generally lack appropriate methodologies to assess participation in terms of its adequacy for achieving an integrated approach.

\section{An evidence-based approach to integration}

The general presumption in the governance literature on coordination is that for each of the three dimensions-sectors, scales, actors, the more engagement the better, although several authors have highlighted challenges that this can pose for coordination (Zusman and Amanuma 2018). In addition, the actors to engage are rarely based on evidencebased scientific tools (Wichelns 2017).

In this article, the main purpose of the BBP is to provide an appropriate foundation on which to (1) improve the efficiency and effectiveness of SDG implementation through the promotion of synergies and the management of trade-offs across sectors and scales and (2) to ensure an inclusive and equitable implementation by bringing together all relevant stakeholders. Relevancy here means those actors whose participation in partnerships can help to manage synergies and trade-offs. The benefits of implementing a research-based approach to integration is that it can improve the information base for identifying relevant actors, making clear the assumptions guiding this selection, which can help to later test and refine the model for actor selection.

To build effective partnerships of this kind, or to assess existing partnerships against these criteria, I propose a framework for identifying relevant actors based on three main pillars: SDG linkages, actors' responsibilities, and dashboards of indicators.

\section{SDG linkages}

To enable integrated SDG implementation, BBPs need to consider linkages across sectors and scales, and in particular, the types of links to include. The boundary placed will ultimately shape the breadth of participation in the partnership as well as the efficiency and equity of implementation.

While interest in interlinkages across sectors is not new (Zusman and Amanuma 2018), aided by the SDGs, research on interlinkages has mushroomed since 2015 covering scientific literature reviews (ICSU 2017; Mohd Hanafiah et al. 2021), qualitative assessment scales (Scharlemann et al. 2020; Singh et al. 2017; Nilsson et al. 2016; Weitz et al. 2014), statistical estimation (Dolley et al. 2020; Pradhan et al. 2017), and modeling (Pedercini et al. 2019; Allen et al. 2017, 2019). A central concern has been to develop the evidence base of interactions. A large body of research 
has mapped linkages between specific goals and targets and the SDGs using tables or interaction matrices (Singh et al 2017; Nerini et al. 2019; Alcamo 2019). At present, the evidence base is large, diverse, and scattered (Alcamo 2019). Although greater knowledge exists of horizontal interactions, i.e., within scale, cross-sector interactions at national or global level (Allen et al. 2018), recent research has begun to examine vertical interactions, i.e., interactions across scales, such as in peri-urban areas (Dolley et al. 2020) and river basins (Vinca 2020; Xu et al. 2021). Case studies of local-level interactions are also increasingly available (Alcamo et al. 2020).

Nexus and WoG type approaches advocate focusing on a few strong interlinkages or potentially all interlinkages, yet neither approach appears satisfactory in terms of efficient implementation (Horan 2020a). In addition, a coordinated response is not necessarily equitable. For instance, nexus approaches can have significant impacts on inequality if goals for social inclusion and equity get "left behind" such as, for example, a Water-Food-Energy nexus that overlooks interactions with poverty (SDG1), gender equality (SDG5), reducing inequalities (SDG10) and justice (SDG16) (van Soest et al. 2019; Soergel et al. 2021). To better support efficient and equitable implementation, one option (followed in this paper) is to focus on all first-order interlinkages, outgoing and incoming, as a means to capture linkages with sociopolitical, equality, human development and governance goals (Alcamo 2019; van Soest et al. 2019). Most studies of a particular SDG's interlinkages report interactions with these "left behind" goals (ICSU 2017; Nerini et al. 2019). Such an approach offers a "local" approximation of issues directly influencing performance and equity.

\section{Actors' responsibilities}

In any collaboration, a clear division of roles and responsibilities helps to enable an effective partnership (Pattberg and Widerberg 2016). While the roles and contributions of different actors to SDG implementation have been discussed elsewhere (Del Rio Castro et al. 2020; Stibbe and Prescott 2020; Zusman and Amanuma 2018), less attention has been devoted to their responsibilities in terms of implementation. Many governments claimed in the first cycle of the VNRs to have assigned implementation responsibilities to different government departments (Kindornay 2019; UNDESA 2019), although only a few country VNRs reported the explicit division of responsibilities (DCCAE 2018). To identify relevant actors, it is of crucial importance, however, to know their implementation responsibilities.

Depending on the application, these responsibilities can be gleamed either from actor's mandates, mission statements or observed activities. A mandate approach is often suitable for public actors. Governments typically assign policy responsibilities across ministries based on their specialist areas (Weitz et al. 2018). For instance, Ireland's SDG National Implementation Plan 2018-2020 divided responsibility for all 169 targets across its 16 departments (DCCAE 2018). Similarly, responsibilities of UN agencies can be gleamed from UN resolutions. Alternatively, mission statements can be used in cases where officially sanctioned mandates are unavailable (Wagner and Torney 2020). Alternatively, the activities of actors can also shed light on responsibilities. Increasingly, studies map the alignment of business operations (Sachs 2018) and universities activities (SDSN 2018) to the SDGs helping to highlight roles and responsibilities in implementation.

\section{Dashboards of indicators}

Monitoring and evaluation is cited as an important success factor for partnerships (Beisheim et al. 2017; Van Tulder et al. 2016; Backstrand 2006). Aided by the development of the global indicator set of 232 official indicators (United Nations 2016), indicator-based assessments of progress on the SDGs can help to refine actor selection and identify challenges and highlight areas where joint efforts might be needed provided indicator selection is based on evidence of interlinkages (Horan 2020a, b).

For example, if reducing marine pollution and sustainable agriculture are linked, then a negative outcome or trend in nutrient run-off from agriculture might signal the need to adjust agriculture policy to account for its marine impact. Whereas if marine pollution and poverty eradiation interact but there is a low level of extreme poverty, then this could indicate that this linkage is not significantly relevant for SDG14.1 achievement. Moreover, it also suggests that stakeholders aligned to extreme poverty eradication may not be relevant actors to include in the BBP for integrated implementation of SDG14.1, whereas actors aligned to achieving sustainable agriculture would probably need to be included in the partnership. In this way, the official set of 232 SDG indicators can provide a consistent framework to guide assessments of interlinked challenges and refine the selection of actors.

Because of the many interlinkages (e.g., SDG14 has 97 target level potential interactions with other SDGs (ICSU 2017)) and the need to coordinate with many actors, a dashboard approach rather than headline index appears to be a better tool to track progress and challenges in interlinked areas. In particular, such a dashboard when combined with gap analysis can guide the lead actors of the BBP on which actors are relevant to cooperate with and on what issues discussions of integration might need to focus (Horan 2020a; Herlitz and Horan 2017). Furthermore, since linkages are often stable over time (although they can change in response to changes in governance, technology, and time (Nilsson 


\begin{tabular}{|c|c|c|c|c|c|}
\hline $\begin{array}{l}\text { 1. Define } \\
\text { Scope }\end{array}$ & $\begin{array}{c}\text { 2. Identify } \\
\text { Interlinkages }\end{array}$ & $\begin{array}{c}\text { 3. Assign } \\
\text { Responsibilities }\end{array}$ & $\begin{array}{l}\text { 4. Select } \\
\text { Indicators }\end{array}$ & $\begin{array}{l}\text { 5. Assess } \\
\text { Challenges }\end{array}$ & $\begin{array}{c}\text { 6. Forge } \\
\text { Partnership }\end{array}$ \\
\hline $\begin{array}{l}\text { Define the scope of the } \\
\text { partnership: } \\
\text { - Issue focus (e.g., } \\
\text { SDG, target) } \\
\text { - Lead actor(s) } \\
\text { Actor types to } \\
\text { engage } \\
\text { - Geographic focus }\end{array}$ & $\begin{array}{l}\text { Map potential } \\
\text { interactions: } \\
\text { - At goal or target level } \\
\text { - First-order linkages } \\
\text { - Horizontal and/or } \\
\text { vertical linkages }\end{array}$ & $\begin{array}{l}\text { Based on actor's: } \\
\text { - Mandates, } \\
\text { - Missions, or } \\
\text { - Activities. }\end{array}$ & $\begin{array}{l}\text { Selection criteria: } \\
\text { - Official indicators } \\
\text { - Relevancy to issue } \\
\text { focus and to linkages } \\
\text { - Limited in number } \\
\text { - Use of proxies }\end{array}$ & $\begin{array}{l}\text { Gap analysis: } \\
\text { - Baseline integrated } \\
\text { assessment } \\
\text { - Data \& } \\
\text { normalization } \\
\text { - Traffic-light } \\
\text { visualization of } \\
\text { challenges } \\
\text { - Radar diagrams } \\
\text { (boundary object) }\end{array}$ & $\begin{array}{l}\text { BBP defined by: } \\
\text { - Lead actor(s) } \\
\text { - Relevant actors } \\
\text { - Monitoring tool } \\
\text { - Challenges }\end{array}$ \\
\hline
\end{tabular}

Fig. 1 Forging a broad-based partnership (BBP) for collaborative SDG implementation

et al. 2018), a dashboard of interconnected SDG indicators may provide a relatively stable monitoring tool for assessing issues and coordinating actors relevant to the BBP.

\section{A data-driven analytic partnership-building framework}

Given a specific challenge such as the implementation of a particular SDG goal, target, or synergy driver, Fig. 1 outlines a framework to forge a broad-based partnership (BBP) from an interaction matrix to harness a collaborative approach to integrated implementation. The procedure has six steps that can be taken in whole or in certain parts: (1) define the scope of the partnership, (2) identify the main interlinkages, (3) assign actors' responsibilities, (4) select the best available indicators, (5) identify and assess the challenges, and (6) forge the partnership.

To summarize, the process starts by defining the scope of the coalition-building problem, i.e., the basic elements of the BBP (Pattberg and Widerberg 2016; Huijstee et al. 2007), namely its issue focus (e.g., the specific SDG goal or target for integrated implementation), the lead actor(s) of the coalition, the actor types to engage (in terms of stakeholder groups) and the geographic focus of the partnership.

The analytic component of the framework builds outwards from the issue focus mapping its main interlinkages with other SDGs, focusing on identifying all first-order interactions at goal or target level. Based on this mapping, the third step assigns actors to each identified linkage based on actor's implementation responsibilities determined either from actor's mandates, mission statements, or activities. The fourth step constructs a dashboard from the best available relevant official SDG indicators which is a tool to assess challenges and coordinate actors. In the fifth step, gap analysis of the dashboard is conducted (a baseline integrated assessment) to assess performance using simple visualization techniques (traffic light visualization) and tools (radar diagrams) to identify challenges and issue areas for integrated implementation. The final step forges the BBP which brings together the lead actor(s), monitoring tool, identified challenges to be addressed and the relevant actors.

The framework can be applied iteratively to actor types, for example, starting first with government departments, then expanding to other stakeholder groups such as UN agencies, local governments, business, universities, civil society organizations. In this way, a broader coalition for integrated implementation can be built at each iteration.

Step 1. Define the partnership's scope. To start, the scope of the partnership needs to be defined. First, the issue focus of the partnership is the specific SDG, target, or synergy driver for integrated implementation such as SDG14, sustainable fishing (Target 14.4) or sustainable supply chain. Second, the lead actor(s) refer here to those actor(s) who have taken lead responsibility for setting up the partnership, for example a public entity mandated to do so, such as a government department (in the case of a government-led partnership to implement SDG14) or UN agency (in an UNled partnership for universal energy access) or IGO (say, EU-led partnership to green the soya supply chain). Third, actor types refer to the stakeholder group(s) to engage in the partnership which determines the breadth of participation and characterization of the partnership's type, e.g., public, public-private, multistakeholder, multilevel. In a solely government or UN partnership, the actor type might be respectively line ministries or UN agencies. Finally, geographic focus refers to the level of SDG implementation (region, country, state, etc.).

Step 2. Map out the main interlinkages. The next step is to map out interlinkages between the issue focus SDG goal or target and the other SDGs. The identification should focus on first-order interactions, distinguishing incoming and outgoing linkages, horizontal and/or vertical linkages. To ensure an evidence-based systematic identification, this step should use an existing study of SDG linkages or apply 
methods from this literature. Results of the analysis should be summarized in an interaction matrix. These data will be an input to partnership discussions. It is not necessary to quantify the interactions rather it suffices to summarize the range of interactions using a qualitative scale in a bar chart (Nilsson et al. 2016), pie chart (Singh et al. 2017), or in a table indicating whether synergies or trade-offs or both are present (Horan 2020b). Such tools are useful to keep track of multiple potential interactions.

Step 3. Assign responsibilities. The third step assigns SDG responsibilities. Given the analysis of interlinkages, the aim of this step is to identify those actors who can help to manage synergies and trade-offs. This step involves first, listing those actors who might be relevant and mapping their responsibilities across SDGs. For instance, a list for government ministries might cover all line ministries in a country, a list for UN agencies, all UN agencies. Various approaches can be used to assign responsibilities: (1) mandates, (2) mission statements, or (3) activities. Given this mapping, for each linkage, the step then entails identifying those actors with responsibility for the SDG goal or target associated with that linkage. In other words, the step singles out actor constellations that can help to manage synergies and/or trade-offs associated with each firstorder connection.

Step 4. Select the best indicators. Given the analysis of interlinkages and actors responsibilities, the next step is to select indicators for each linkage and actor constellation. Following (Horan 2020a, b), four criteria are proposed for indicator selection. First, coverage of official SDG indicators, to ensure transparency in the selection and adherence to official guidelines. Second, relevancy to the issue focus, i.e., the official indicator for the specific "entry point" goal or target should be used. Third, relevancy to the linkages which means selecting the best available official indicator relevant to the goal or target identified from the analysis of linkages. Fourth, to ensure an effective monitoring framework, the selection should be limited to make for a parsimonious indicator set. Since data gaps frequently arise with official indicators (United Nations 2020), proxy indicators should be used to broaden the scope of assessment according to the following steps: step A, if the goal or target has a Tier 1 indicator, select this indicator; step B, if it is official indicator has a Tier 2 classification (data are unavailable) or Tier 3 classification (it lacks established methodology), a suitable proxy should be sought and if available selected; and step C, if no suitable proxy is available, the goal or target should be excluded from the dashboard.

Step 5. Identify and assess the challenges. To measure performance on each indicator, baseline analysis should be conducted. Given data, to make indicators comparable, one approach popular in SDG assessments is to normalize the observed value using min-max normalization (SDSN 2021, OECD 2008). To identify strengths and challenges, a traffic light color-coding scheme can help to visualize performance (SDSN 2021, Horan 2020a). One approach is to take differences in normalized values of 20 points to be significant and to use an equal interval technique for grading challenges (Glass and Newig 2019, Horan 2020b). To identify where efforts might be needed, radar diagrams are useful to visualize performance against each target for the entire dashboard. Assessment can be taken in two steps: first, an assessment of performance on the entry point goal or target (ignoring linkages) and second, an integrated assessment of performance (that accounts for the first-order interlinkages).

Step 6. Forge the partnership. Once a performance profile has been ascertained, challenges can be combined with mappings of responsibilities and recommendations made on who the lead actor(s) should engage, in what areas coordinated actions might be needed, and the depth of the challenge faced in those areas. The purpose of the tool is to bring the relevant actors to the discussion table. The focus of the approach is on doing this in a systematic way.

\section{Illustrative examples of the framework}

Connecting SDG interactions and specific types of partnerships has powerful potential because it provides an evidence-based framework and institutional arrangement to operationalize collaborative implementation that can be used to address synergies and trade-offs across diverse actors as well as a yardstick to assess participation in such partnerships. While integration is by no means guaranteed, the proposed approach offers a strategic framework to bring relevant actors together to negotiate joint actions for integrated implementation.

The approach is predicated on having good information on SDG interactions, actors' responsibilities, relevant indicators, and sufficient data for the monitoring tool to assess areas for integration and to coordinate actors. While progress has been made in all these areas, the greatest knowledge gaps appear on SDG interactions across scales and actors' responsibilities or alignment to the SDGs.

In this section, four examples are discussed to shed light on ways the tool can be used in practice and some problems that can arise in applications, namely the types of interactions that can be considered, how to determine responsibilities and how to single out actors who might be relevant. I first start on familiar ground, discussing the results of a fully-fledged example applied to horizontal policy integration at national level, covered in (Horan 2020a). Then, I discuss a broader range of potential applications not normally considered in the SDG interaction literature. 
The examples help to elucidate new directions for research, important knowledge gaps and outline some ways to deal with these. A summary of the cases is given in Table 2.

\section{Example 1. Policy cooperation across line ministries}

While much current work on SDG interactions is focused on policy integration across line ministries, much of this work is based on a nexus approach (Weitz et al. 2014, 2017). In contrast, a first-order approach emphasizes a wider range of linkages and thus a broader level of engagement across ministries to better support efficient and equitable implementation.

In a recent study on which government departments in Ireland need to cooperate for integrated SDG14 implementation, Horan (2020a) applied the framework to four SDG14 targets-reducing marine pollution (14.1), sustainable fishing (14.4), marine protection (14.5) and raising economic benefits (14.7). Taking the DHPLG as Ireland's lead department for marine affairs, to apply the framework, the author used the ICSU (2017) analysis of SDG14 linkages to identify potential synergies and trade-offs between SDG14 and the other SDGs. Analysis focused on all first-order interactions at goal level. Identification of department's SDG responsibilities was taken from Ireland's SDG National Implementation Plan 2018-2020 which divided responsibility for implementing the 17 SDGs and 169 targets among the 16 government departments in Ireland at this time (DCCAE 2018). Indicators selected for the dashboard were drawn from SDSN's global SDG indicator set (SDSN 2019), which includes several proxy indicators that helped to broaden the scope of the assessment.

The complete list of indicators selected for the four targets based on steps $1-5$ can be found in Horan (2020a). The SDG14 dashboard consisted of 33 indicators, 4 marine indicators and 29 "linkage" indicators. Out of the 16 government departments in Ireland in this period, 12 departments were identified as being directly connected to SDG14 achievement. Overall, the integrated baseline assessment identified 18 challenges and 10 government departments over which engagement and coordination appear to be needed to achieve SDG14 in an integrated way (see Fig. 2). Specifically, the study recommended Ireland's lead department for marine affairs (DHPLG) cooperate with 9 other departments in fifteen policy areas (Fig. 2).

In this application, the BBP consists of 10 government departments. By contrast, WoG approaches would propose cooperation among all 16 departments. On the other hand, a nexus approach would restrict cooperation to 2-3 departments. The framework thus proposes an intermediate level

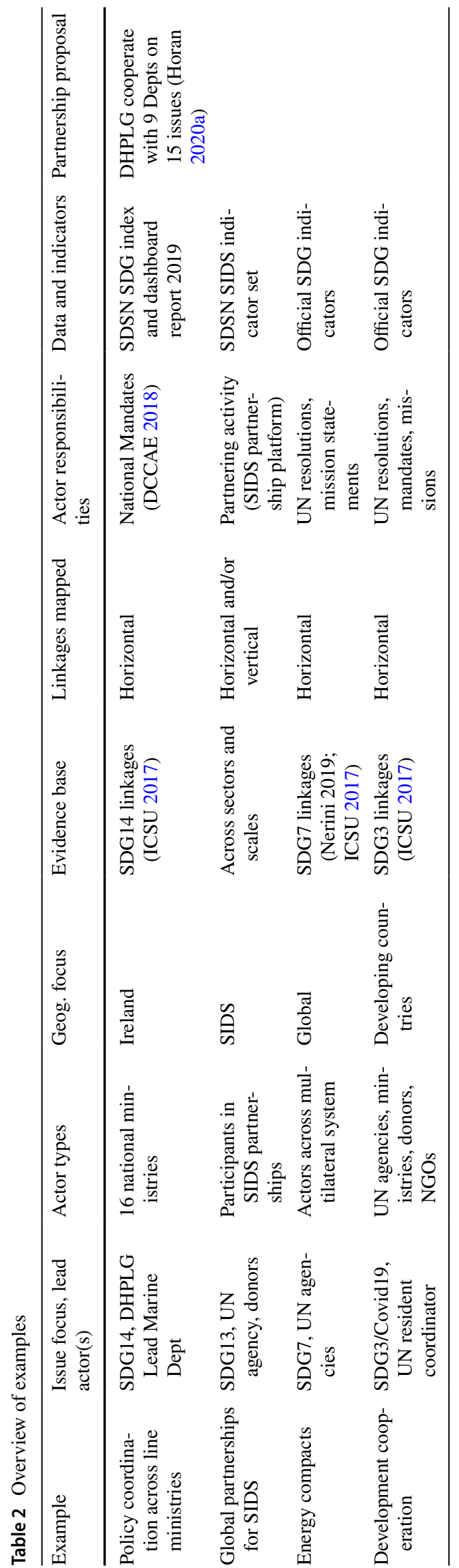




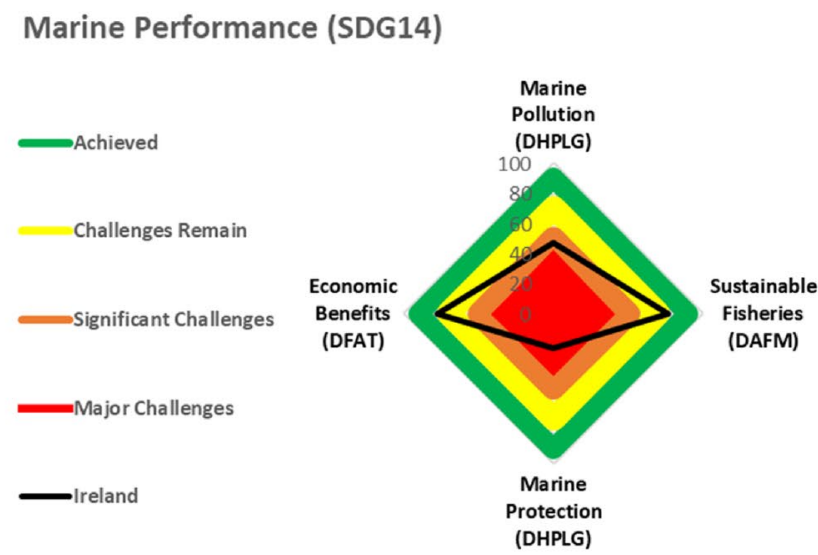

Impacts

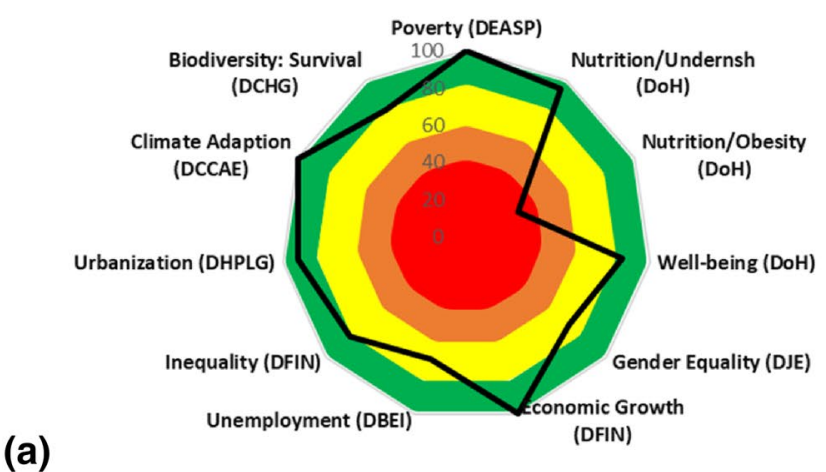

(a)

Fig. 2 Adapted from Horan (2020a). Using a variant of Steps 1-5, Horan (2020a) conducted an integrated assessment of Ireland's baseline for implementing SDG14 using ICSU (2017) analysis of SDG14 linkages, SDSN's global indicator set (SDSN 2019) and a mapping of government department's SDG responsibilities contained in Ireland's SDG Implementation Plan (DCCAE 2020). To express potential causal interrelations, indicators linked to SDG14 achievement were divided into three components: pressures, impacts and responses (see Horan 2020a, b). A representation of the country's performance against each target is provided by the radar diagrams in (a). Traffic light color coding was used to identify strengths and challenges. Country-specific challenges were combined with the mappings of departmental SDG responsibilities to develop recommendations on which departments need to cooperate with and in what areas actions

of cooperation, significantly less than full cooperation but considerably more than a nexus approach would propose. In addition, it identifies 18 policy areas for integration thus offering a useful starting point for inter-ministry discussions on integrated SDG14 policymaking. In particular, it suggests the BBP should focus on enabling joined up actions and inter-ministry cooperation on these challenges.

\section{Pressures}

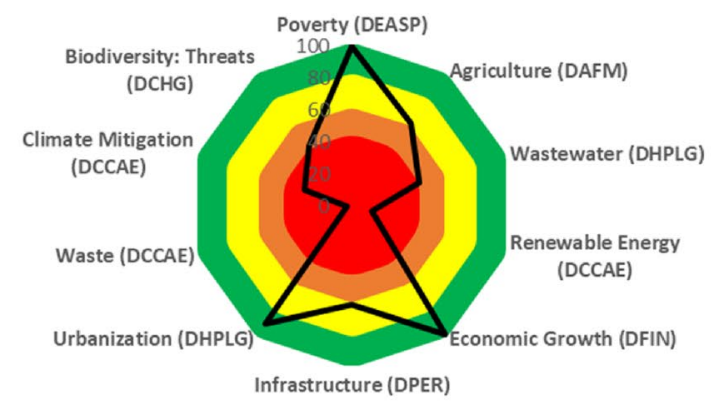

Responses

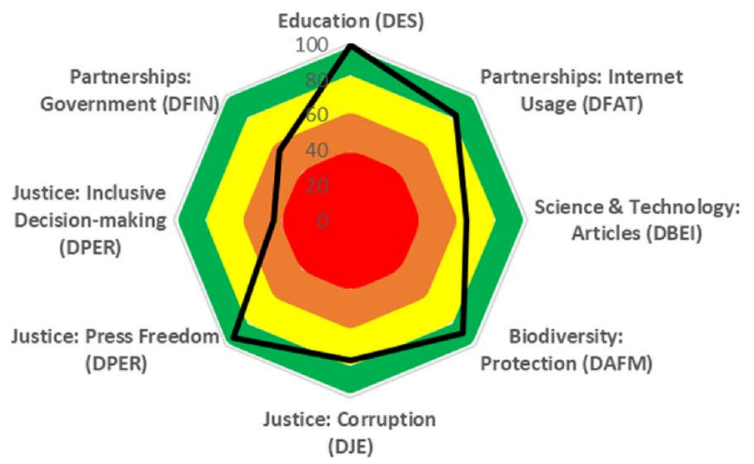

might be needed (b). The rows of the Table list departments to cooperate and entries highlight policy areas for discussion. Columns categorize each policy area according to four components: marine performance, pressures, impacts, and responses. Policy areas are graded according to assessment in (a): yellow: challenges remain; orange: significant challenges; red: major challenges. *DHPLG: Department of Housing Planning and Local Government. DAFM: Department of Agriculture, Food, and Marine. DFAT: Department of Foreign Affairs and Trade. DCCAE: Department of Communications, Climate Action, and Environment. DFIN: Department of Finance. DPER: Department of Public Expenditure and Reform. DCHG: Department of Culture, Heritage, and the Gaeltacht. DoH: Department of Health. DBEI: Dept. of Business, Enterprise, and Innovation. DJE: Department of Justice and Equality

\section{Example 2. Global partnerships for SDG13 implementation in SIDS}

Owing to their small size, and vulnerabilities to global environmental change, SIDS are especially dependent on transnational partnerships to achieve sustainable development (United Nations 2017; UNEP 2014). The SIDS Partnership Framework was launched in 2014 with the aim of catalyzing new partnerships and supporting existing 


\begin{tabular}{c|l|l|l|l}
\hline Departments* & SDG14 & Pressures & Impacts & Responses \\
\hline DAFM & Sustainable Fisheries & Sustainable Agriculture & & \\
\hline \multirow{2}{*}{ DBEI } & & & Employment & Innovation \\
\hline \multirow{2}{*}{ DCCAE } & & Climate Mitigation & & \\
\cline { 3 - 5 } & & Renewable Energy & & \\
\cline { 3 - 5 } & & Municipal Waste & & \\
\hline DFIN & & Biodiversity Threats & & Finance \\
\hline DFAT & Economic Benefits & & & \\
\hline DoH & & & Nutrition/Obesity & \\
\hline \multirow{2}{*}{ DHPLG } & Marine Protection & Wastewater Treatment & & \\
\cline { 2 - 5 } & Marine Pollution & & Gender Equality & Corruption \\
\hline DJE & & & & Inclusive Decision \\
& & Sustainable & Making \\
\hline
\end{tabular}

(b)

Fig. 2 (continued)

partnerships (UNDESA 2019). To date, over 500 partnerships have registered with participants drawn from international institutions, national governments, NGOs, industry associations, research institutions and grassroots organizations.

To forge global partnerships for SDG implementation in SIDS, or to assess participation in such partnerships, one obstacle concerns the absence of a readily available list of actors who might be relevant. Here, the universe of relevant actors is global in scale, covering local and transnational actors. One approach could use the database of partnerships registered in the SIDS Action Platform, which provides information on the set of entities participating in at least one registered partnership. Since these organizations participate voluntarily, using this registry list would correspond to a "coalition of the willing". In this limited sense, a database approach could help to identify relevant partners.

To apply the framework to say integrated SDG13 implementation in a particular SIDS, several studies of SDG13 linkages are available (Nerini et al. 2019; IPCC 2018), with some using empirical evidence from SIDS (Fuldauer et al. 2021). Based on the list of organizations participating in SIDS partnerships, implementation responsibilities could be gleamed from observed partnering activities to highlight actors' alignment to the SDGs (in addition to consulting organization's mandates/mission statements). A dashboard can then be assembled using SDSN's SIDS indicator set (SDSN 2021), first-order challenges assessed at countrylevel, and recommendations made on those actors whose participation could help to deliver a more integrated approach to transnational implementation.

\section{Example 3. Energy compacts for SDG7 implementation}

At the international level, the brokering of partnerships is largely event driven (Chan et al. 2021; Pattberg et al. 2012; Andonova and Levy 2003). While many commitments are often announced at high-level events (e.g., UN Climate Summits), participation in these events is typically based on actor's institutional memberships and networks rather than evidence-based methods to engage stakeholders (Pattberg et al. 2018). In addition, many events promote an individual goal approach. For example, climate events mostly focus on "bridging" the emissions gap despite strong connections between climate action and other aspects of sustainable development (Chan et al. 2020, 2021).

To support integrated implementation, the framework could be applied to specific events to identify relevant actors to engage. For instance, similar to the Race to Net Zero dialogues led by UNFCCC, UN Energy (in collaboration with UNDESA) oversaw the preparatory process for the Highlevel Dialogue in September 2021 to accelerate progress on Clean Energy (SDG7). The aim of the dialogue was to mobilize commitments ("Energy Compacts") across the multilateral system in areas such as universal energy access and energy transition. Each thematic discussion was led by 
a UN agency or Intergovernmental Organization (IGO) and participation in these discussions is for the most part limited to organizations with UN consultative status.

To assess participation in these dialogues and to bring together relevant actors from across the multilateral system, the framework could be applied to each thematic challenge and actor types covering UN agencies, IGOs, and NGOs. Given the issue, e.g., universal energy access, energy transition, mappings of SDG7 interactions (e.g., ICSU 2017; Nerini et al. 2017; McCollum et al. 2018) could be applied at global level. A dashboard could then be constructed using SDG data and indicators to assess the main issues facing the planet on SDG7 and the challenges in interconnected areas. To gleam actor's responsibilities, the UN maintains a list of all NGOs in consultative status with the UN. Therefore, mission statements for these organizations and the mandates of UN agencies and IGOs could help identify actors' responsibilities.

\section{Example 4. Integrated multilateral responses to crises}

To deal with current and emerging crises, the pandemic has highlighted the importance of effective transnational cooperation, especially for developing countries (Klingebiel and Gonsior 2020). Over a year ago, the UN reformed its development system to improve coordination among UN agencies to help deliver coordinated support to developing countries and progress on the SDGs (United Nations 2019b). Each country's Resident Coordinator (RC) acts as a focal point in the system to align UN agencies to the government's national development priorities (United Nations 2019b; Chimhowu et al. 2019). Typically, when a crisis happens, governments request support from the UN and the 40 or so UN agencies respond often in a siloed uncoordinated manner, assessing the impact of the crisis in its issue area and making recommendations based on its particular focus, e.g., environmental issues (UNEP), social protection (UNDP), capacity of the health system (WHO), etc.

To assist the RCs and UN Country Teams (UNCTs) on which agencies to engage and on what issues, the framework could be applied to the specific crisis related SDG using offthe-shelf SDG mappings, expert appraisal of linkages and/or stakeholder consultation. A dashboard could be constructed monitoring progress in related areas using country-level SDG data and indicators (SDSN 2021) with responsibilities determined from UN agencies mandates and mission statements. To broaden the coalition, the framework could be applied to other stakeholder groups including the country's government ministries, donors, and NGOs operating in the country. Using the UN registry of NGOs in consultative status, UN agencies and UNCTs could refine this list to NGOs operating in the country. Information on ministries' responsibilities can be supplied by the national government. Similarly, the OECD records member state donations and their activities. An advantage of the approach is that if streamlined (e.g., supported by a technical team at UNCT working in collaboration with ministries and technical partners) it could provide a way to systematically approach relevant actors and clarify their roles and responsibilities in addressing the crisis to help deliver a more coordinated response.

\section{Discussion}

\section{Coalition building and data gaps}

The examples suggest that an iterative application of the framework aimed at building coalitions one stakeholder group at a time is feasible in several contexts important for accelerating action on the SDGs. However, large knowledge gaps particularly for SDG interactions across scales are likely to restrict its application to certain stakeholder groups and dimensions without further progress in this area.

Although the examples did not attempt to deal with vertical integration in a substantive way, the strategies proposed to identify relevant actors at international and national levels appear less useful for integration across scales and applications at subnational level. For example, inventories such as government mappings and UN registries are only available for a few stakeholder groups (ministries, UN agencies, NGOs). Local actors and grassroots organizations tend to lack visibility in these registries (Chan et al. 2021). While NGOs, subnational governments and local communities can help to identify lists of actors who might be relevant at subnational levels, SDG interaction studies and dashboards tend to have greater coverage at national level.

Promising developments that could broaden the frameworks applicability include the rapidly evolving literature on subnational interactions (Alcamo et al. 2020; Xu et al. 2021), increasing emergence of SDG open data portals and citizen science data at subnational levels (Allen et al. 2021b; de Sherbinin et al 2021), as well as geospatial data and methods for local stakeholder identification (SDSN et al. 2019). Continued developments in these areas offer unprecedented opportunities to enable more data-driven approaches to partnerships.

\section{Technical capabilities and stakeholder engagement}

A second issue concerns the technical capabilities and resources that lead actors require to apply the different steps of the framework.

At first glance, the framework appears to triple the technical demands highlighted in the literature on SDG interactions 
(Allen et al. 2021a, b). However, the aim of applications is to identify relevant actors rather than to precisely assess actual interactions. It is envisaged that once the partnership is implemented, stakeholders working in partnership will shed greater light on actual interactions in specific contexts (Nilsson et al. 2018). Furthermore, only certain steps of the framework need to be applied, e.g., dispensing with indicator steps 4 and 5 with stakeholders assessing challenges in step 5. The main point here is that applications of the framework can strike different balances between technical requirements and stakeholder engagement.

While the examples suggest public actors such as developed country governments, UN Agencies, UNCTs should invest in dedicated multi-disciplinary teams and technical capacities to harness collaborative implementation, a priority for the research community more generally should be to develop low-cost rapid assessment (LCRA) approaches for contexts where resources and technical capabilities are low (Allen et al. 2021a, b). LCRA might include the use of generic off-the-shelf mappings or interaction matrices for specific SDGs and targets or guideline reports that standardize SDG responsibilities for different actor types. LCRAs combined with stakeholder consultation and technical assistance could significantly reduce technical requirements and broaden applications to many contexts.

\section{How do priorities get selected in different contexts?}

Careful consideration needs to be given to costs and benefits of real-world applications of BBPs. Partnerships can entail significant upfront investment, transaction costs, process management and dedicated leadership (Pattberg and Widerberg 2016). In addition, there are opportunity costs to partnering (forgone actions). Ideally, applications should focus on entry points where accelerated joint actions can deliver greatest impact for the SDGs Decade of Action and where there is broad stakeholder buy-in.

Though the framework may appear to support top-down approaches to implementation, it is silent on which entry points are selected and through what governance process. For instance, the framework could be aligned with goals prioritized through national policy processes (VNRs, National Development Plans) or expert-driven processes such as scientific panels (IPCC, Science Panel for the Amazon). Alternatively, priorities could come from deliberative procedures, e.g., deliberative mini-publics (Curato et al. 2021; Farrell et al. 2019; Elstub et al. 2021) or collective visioning processes (Beck et al. 2021; Scoones et al. 2020; Beck and Forsyth 2020; Beck and Mahony 2017). Since partnerships are a mechanism to deliver "agreed" goals, regardless of how the goal is actually agreed, a partnership approach can align either with expert-centered ("bring the stakeholders on board" views) or "co-productionist" approaches ("bring the stakeholders together") (Oomen et al. 2021; Jasanoff 2004).

A second key issue concerns how synergies and trade-offs might be managed through partnerships. While partnerships can help to bring together different stakeholders to negotiate SDG interactions and prioritize different courses of action, this leaves open the question of how joint actions will be negotiated in practice. Here, issues of power, agency, and control will be important (Beck et al. 2021; Stoddard et al. 2021). The partnership literature recognizes unequal patterns of engagement as a risk of partnerships especially where unequal resource relations result in exclusion or cooption of smaller partners (Chan et al. 2019; Hale 2004). Various means are available to minimize this challenge, such as internal governance arrangements, decision-making processes, investments in actors capacity to partner, trained stakeholder representatives for vulnerable groups, and professional orchestrators (Prescott and Stibbe 2020; Stibbe and Prescott 2020; Fowler and Biekart 2017).

\section{Conclusion}

Whereas the focus in the literature on SDG implementation has been on identifying and assessing linkages, developing tools, and gathering evidence on SDG interactions, less attention has been devoted to how SDG linkages can be used to foster collaborative approaches to integrated implementation. A key challenge for operationalizing such an approach is knowing the right actors to engage, on what challenges, and for what purpose. It is acknowledged that linkages across sectors, scales, and actors could provide an evidence base to assess and forge partnerships for implementation, however, technical tools that could help to identify relevant partners have been notably lacking in the literature.

The role of indicators in promoting an integrated approach although alluded to by several scholars (Alcamo 2019) has been insufficiently examined. Indicators in related issues areas can act as useful communication devices between actors helping to frame and coordinate actions across diverse actors (Horan 2020a). The dashboard approach to engagement and coordination presented here offers an interesting avenue for future research on SDG implementation.

Mapping responsibilities is a major challenge. Not enough attention has been given to roles and responsibilities of different stakeholder groups in integrated implementation. Furthermore, institutional arrangements to support collaborative implementation are also needed (Breuer et al. 2019b; Tosun and Leininger 2017; Zusman and Amanuma 2018; Horan 2019b; Singh et al. 2021). The issue of how to institutionalize and incentivize participation and how to bring relevant actors on board is an important issue. Common challenges are a lack of organizational 
structures to support partnering, and inadequate human resources, skills, and funds to partner (UNDESA 2016). Though not addressed in this paper, enabling collaborative implementation requires not just technical tools to bring actors together but also deeper institutional and organization reforms to fully operationalize this approach.

Acknowledgements The author would like to thank Professor David Farrell and two anonymous reviewers for their suggestions on how to improve the paper and the guest editors of the Special issue for the invitation to write this article. This research received funding from the European Commission and Irish Research Council Horizon 2020 research and innovation program under the Marie Sklodowska-Curie grant agreement 713279 .

Funding David Horan: H2020 Marie Skłodowska-Curie Actions, 713279.

Open Access This article is licensed under a Creative Commons Attribution 4.0 International License, which permits use, sharing, adaptation, distribution and reproduction in any medium or format, as long as you give appropriate credit to the original author(s) and the source, provide a link to the Creative Commons licence, and indicate if changes were made. The images or other third party material in this article are included in the article's Creative Commons licence, unless indicated otherwise in a credit line to the material. If material is not included in the article's Creative Commons licence and your intended use is not permitted by statutory regulation or exceeds the permitted use, you will need to obtain permission directly from the copyright holder. To view a copy of this licence, visit http://creativecommons.org/licenses/by/4.0/.

\section{References}

Africa CDC (2021) Africa Centers for Disease Control and Prevention: annual report 2020. Available at https://africacdc.org/ download/annual-progress-report-2020/

Alcamo J (2019) Water quality and its interlinkages with the sustainable development goals. Curr Opin Environ Sustain 36:126-140

Alcamo J, Thompson J, Alexander A, Antoniades A, Delabre I (2020) Analysing interactions among the sustainable development goals: findings and emerging issues from local and global studies. Sustain Sci 15:1561-1572

Allen C, Metternicht G, Wiedmann T (2017) An iterative framework for national scenario modelling for the sustainable development goals (SDGs). Sustain Dev 25(5):372-385

Allen C, Metternicht G, Wiedmann T (2018) Initial progress in implementing the sustainable development goals (SDGs) - a review of evidence from countries. Sustain Sci 13:1453-1467. https://doi.org/10.1007/s11625-018-0572-3

Allen C, Metternicht G, Wiedmann T, Pedercini M (2019) Greater gains for Australia by tackling all SDGs but the last steps will be the most challenging. Nat Sustain 2(11):1041-1050

Allen C, Smith M, Rabiee M (2021a) A review of scientific advancements in datasets derived from big data for monitoring the sustainable development goals. Sustain Sci 16:1701-1716. https:// doi.org/10.1007/s11625-021-00982-3

Allen C, Metternicht G, Wiedmann T (2021b) Priorities for science to support national implementation of the sustainable development goals: a review of progress and gaps. Sustain Dev. https:// doi.org/10.1002/sd.2164
Andonova L, Levy M (2003) Franchising global governance: Making sense of the Johannesburg type II partnerships. In: Stocke OS, Thomessen OB (eds) Yearbook of international cooperation on environment and development 2003/04. Earthscan, London, UK, pp 19-31

Backstrand K (2006) Multi-stakeholder partnerships for sustainable development: rethinking legitmacy, accountability and effectiveness. Eur Environ 16:290-306

Backstrand K, Kuyper JW (2017) The democratic legitimacy of orchestration: UNFCCC, non-state actors, and transnational climate governance. Environ Polit 26(4):764-788

Beck S, Mahony M (2017) The IPCC and the politics of anticipation. Nat Clim Change 7:311-313. https://doi.org/10.1038/nclim ate 3264

Beck S, Jasanoff S, Stirling A, Polzin C (2021) The governance of sociotechnical transformations to sustainability. Curr Opin Environ Sustain 49:143-152

Beisheim M, Fritzsche F (2021) Networked multilateralism: ECOSOC and HLPF reviews as window of opportunity. Guest article, IISD SDG Knowledge Hub. Published on 20 January 2021. Available at https://sdg.iisd.org/commentary/guest-artic les/networked-multilateralism-ecosoc-and-hlpf-reviews-as-window-of-opportunity

Beisheim M, Simon N (2018) Multistakeholder partnerships for the SDGs: actors' view on UN metagovernance. Glob Gov 24:497-515

Bennich T, Weitz N, Carlsen H (2020) Deciphering the scientific literature on SDG interactions: A review and reading guide. Sci Total Environ 728:138405

Breuer A, Janetschek H, Malerba D (2019a) Translating sustainable development goal (SDG) interdependencies into policy advice. Sustainability 11(7):2092. https://doi.org/10.3390/su11072092

Breuer A, Leininger J, Tosun J (2019b) Integrated policymaking: choosing an institutional design for implementing the sustainable development goals (SDGs); Discussion paper 2019/14. German Development Institute, Bonn, Germany

Caplan K (2013) Taking the mythology out of partnerships: a view from the ground up. London, UK. Available at http://www.bpdws. org/web/d/DOC_359.pdf\%3FstatsHandlerDone\%3D1. Accessed on 16 August 2021

Chan S, Falkner R, Goldberg M, van Asselt H (2018) Effective and geographically balanced? An output-based assessment of nonstate climate actions. Clim Policy 18(1):24-35. https://doi.org/ $10.1080 / 14693062.2016 .1248343$

Chan S, Iacobuta G, Hägele R (2020) Maximising goal coherence in sustainable and climate-resilient development? Polycentricity and coordination in governance. In: Chaturvedi S, Janus H, Klingebiel S, Li X, de Mello e Souza A, Sidiropoulos E, Wehrmann D (eds) The Palgrave handbook of development cooperation for achieving the 2030 agenda. Palgrave Macmillan, Cham, pp 25-50

Chan S, Boran I, van Asselt H, Ellinger P, Garcia M, Hale T, Shrivastava MK (2021) Climate ambition and sustainable development for a new decade: a catalytic framework. Glob Pol 12(3):245-259

Chimhowu AO, Hulme D, Munro LT (2019) The 'New' national development planning and global development goals: processes and partnerships. World Dev 120:76-89

Curato N, Farrell D, Geissel B, Gronlund K, Mockler P et al (2021) Deliberative mini-publics: core design features. Bristol University Press, Bristol

DCCAE (2018) The sustainable development goals national implementation plan 2018-2020. Department of Communications, Climate Action and the Environment. Available at https://www.dccae.gov. ie/en-ie/environment/topics/sustainable-development/sustainabledevelopment-goals/Pages/default.aspx 
de Sherbinin A, Bowser A, Chuang TR, Cooper C, Danielsen F, Edmunds R, Sivakumar K (2021) The critical importance of citizen science data. Front Clim 3:20-27

Del Rio Castro G, Gonzalez Fernandez MC, Uruburu Colsa A (2020) Unleashing the convergence amid digitalization and sustainability towards pursuing the sustainable development goals (SDGs): a holistic review. J Clean Prod 280:122204. https://doi.org/10. 1016/j.jclepro.2020.122204

Dodds F (2015) Multi-stakeholder partnerships. Making them work for the post-2015 development agenda. Study commissioned by UNDESA

Dolley J, Marshall F, Butcher B, Reffin J, Robinson JA, Eray B, Quadrianto N (2020) Analysing trade-offs and synergies between SDGs for urban development, food security and poverty alleviation in rapidly changing peri-urban areas: a tool to support inclusive urban planning. Sustain Sci 15(6):1601-1619

Elstub S, Carrick J, Farrell DM, Mockler P (2021) The scope of climate assemblies: lessons from the climate assembly UK. Sustainability 13(20): 11272

Farrell DM, Suiter J, Harris C (2019) 'Systematizing' constitutional deliberation: the 2016-18 citizens' assembly in Ireland. Irish Polit Stud 34(1):113-123. https://doi.org/10.1080/07907184. 2018.1534832

Glass LM, Newig J (2019) Governance for achieving the sustainable development goals: how important are participation, policy coherence, reflexivity, adaption and democratic institutions? Earth Syst Governance 2:100031. https://doi.org/10.1016/j. esg.2019.100031

Global Partnership for Sustainable Development Data (2020) Fiveyear report 2015-2020

Hale T, Roger C (2014) Orchestration and transnational climate governance. Rev Int Organ 9:59-82

Herlitz A, Horan D (2017) A Model and Indicator of Aggregate Need Satisfaction for Capped Objectives and Weighting Schemes for Situations of Scarcity. Social Indicators Research 133(2) 413-430. https://doi.org/10.1007/s11205-016-1373-7

Horan D (2019a) A new approach to partnerships for SDG transformations. Sustainability 11(18):4947. https://doi.org/10.3390/su111 84947

Horan D (2019b) Compensation strategies to enact new governance frameworks for SDG transformations. Public Sector Economics 43(4) 375-400. https://doi.org/10.3326/pse.43.4.3

Horan D (2020a) Enabling integrated policymaking with the sustainable development goals: an application to Ireland. Sustainability 12(18):7800. https://doi.org/10.3390/su12187800

Horan D (2020b) National baselines for integrated implementation of an environmental sustainable development goal assessed in a new integrated SDG index. Sustainability 12(17):6955. https://doi.org/ $10.3390 /$ su 12176955

Horan D (2021) Towards a portfolio approach: partnerships for sustainable transformations. Global Policy. https://doi.org/10.1111/ 1758-5899.13020

Huijstee MM, Francken M, Leroy P (2007) Partnerships for sustainable development: a review of current literature. Environ Sci 4:75-89

ICSU (2017) A guide to SDG interactions: from science to implementation. International Council for Science, Paris

Jänicke M (2006) The 'Rio Model' of environmental governance-a general evaluation

Jasanoff S (2004) The idiom of co-production. States of knowledge. Routledge, Milton Park, pp 12-23

Kindornay S (2019) Progressing national SDG implementation: an independent assessment of the voluntary national review reports submitted to the United Nations high-level political forum in 2018. Canadian Council for International Co-operation, Ottawa, ON, Canada
Klingebiel S, Gonsior V (2020) Development policy from a systemic perspective: changes, trends and its future role within a broader framework for transnational co-operation. Rev Brasil Polít Int 63(2):1-22

Lui S, Kuramochi T, Smit S, Roelfsema M, Hsu A, Weinfurter A, Chan S, Hale T, Fekete H, Lütkehermöller K, de Villafranca Casas MJ, Nascimento L, Sterl S, Höhne N (2020) Correcting course: the emission reduction potential of international cooperative initiatives. Clim Policy 21(2):232-250

McCollum DL, Echeverri LG, Busch S, Pachauri S, Parkinson S, Rogelj J, Krey V, Minx JC, Nilsson M, Stevance AS, Riahi K (2018) Connecting the sustainable development goals by their energy inter-linkages. Environ Res Lett 13(3):033006

Mohd Hanafiah K, Abd Mutalib AH, Miard P, Goh CS, Mohd Sah SA, Ruppert N (2021) Impact of Malaysian palm oil on sustainable development goals: co-benefits and trade-offs across mitigation strategies. Sustain Sci 1-23

Nilsson M, Weitz N (2019) Governing trade-offs and building coherence in policy-making for the 2030 agenda. Politics Gov 7(4):254-263. https://doi.org/10.17645/pag.v7i4.2229

Nilsson M, Griggs D, Visbeck M (2016) Map the interactions between sustainable development goals. Nature 534:320-322

Nilsson M, Chisholm E, Griggs D et al (2018) Mapping interactions between the sustainable development goals: lessons learned and ways forward. Sustain Sci 2018(13):1489-1503. https://doi.org/ $10.1007 / \mathrm{s} 11625-018-0604-\mathrm{z}$

OECD (2016) Better policies for sustainable development 2016: a new framework for policy coherence. 292. OECD Publishing, Paris. https://doi.org/10.1787/9789264256996-en

Oomen J, Hoffman J, Hajer MA (2021) Techniques of futuring: on how imagined futures become socially performative. Eur J Soc Theory 27:1-19. https://doi.org/10.1177/1368431020988826

One by One UHC Report (2020) Africa Leads the Way: Harnessing Multi-sectoral Collaboration to Achieve UHC. Report prepared by The Access Challenge and Harvard Global Health Institute, Boston

Pattberg P, Widerberg O (2016) Transnational multistakeholder partnerships for sustainable development: conditions for success. Ambio 45:42-51

Pattberg PH, Biermann F, Chan S, Mert A (eds) (2012) Public private partnerships for sustainable development. Emergence, influence and legitimacy. Edward Elgar, Cheltenham, UK

Pattberg P, Chan S, Sanderink L, Widerberg O (2018) Linkages: understanding their role in polycentric governance. In: Jordan A, Huitema D, van Asselt H, Forster J (eds) Governing climate change: polycentricity in action. Springer, London, pp 169-189

Pradhan P, Costa L, Rybski D, Lucht W, Kropp JP (2017) A systematic study of sustainable development goal (SDG) interactions. Earth Future 5(11):1169-1179

Prescott D, Stibbe D (2020) Partnership platforms for the SDGs: learning from practice. The Partnering Initiative, and UNDESA. Available at https://sdgs.un.org/publications/partnership-platf orms-sdgs-learning-practice-24568

Reinsberg B, Westerwinter O (2019) The global governance of international development: documenting the rise of multi-stakeholder partnerships and identifying underlying theoretical explanations. Rev Int Organ 16(1):59-94

Sachs JD, Schmidt-Traub G, Kroll C, Lafortune G, Fuller G (2019) Sustainable development report 2019. Bertelsmann Stiftung and Sustainable Development Solutions Network, New York

Scharlemann JP, Brock RC, Balfour N, Brown C, Burgess ND, Guth MK, Kapos V (2020) Towards understanding interactions between sustainable development goals: the role of environment-human linkages. Sustain Sci 15(6):1573-1584

Scoones I, Stirling A, Abrol D, Atela J, Charli-Joseph L, Eakin H, Ely A, Olsson P, Pereira L, Priya R, van Zwanenberg P, Yang L (2020) 
Transformations to sustainability: combining structural, systemic and enabling approaches. Curr Opin Environ Sustain 42:65-75. https://doi.org/10.1016/j.cosust.2019.12.004

SDSN (2019) Towards more sustainability in the soy supply chain: How can EU actors support zero deforestation and SDG efforts? For Deutsche Gesellschaft für Internationale Zusammenarbeit (GIZ) GmbH on behalf of the German Federal Ministry for Economic Cooperation and Development (BMZ).

Singh GG, Cisneros-Montemayor AM, Swartz W, Cheung W, Guy JA, Kenny T-A, McOwen CJ, Asch R, Geffert JL, Wabnitz CC, Sumaila R, Hanich Q, Ota Y (2017) A rapid assessment of cobenefits and trade-offs among sustainable development goals. Mar Policy 93:223-231. https://doi.org/10.1016/j.marpol.2017.05.030

Singh GG, Oduber M, Cisneros-Montemayor AM, Ridderstaat J (2021) Aiding ocean development planning with SDG relationships in small island developing states. Nat Sustain 4:573-582

Soergel B, Kriegler E, Weindl I, Rauner S, Dirnaichner A, Ruhe C, Hofmann M, Bauer N, Bertram C, Bodirsky BL, Leimbach M (2021) A sustainable development pathway for climate action within the UN 2030 Agenda. Nat Clim Chang 11(8):656-664

Stafford-Smith M, Griggs D, Gaffney O, Ullah F, Reyers B, Kanie N, Stigson B, Shrivastava P, Leach M, O'Connell D (2016) Integration: the key to implementing the sustainable development goals. Sustain Sci 12(6):911-919

Stibbe D, Prescott D (2020) The SDG partnerships guidebook: a practical guide to building high impact multi-stakeholder partnerships for the sustainable development goals. The Partnering Initiative and UNDESA

Stibbe DT, Reid S, Gilbert J (2020) Maximizing the impact of partnerships for the SDGs. The partnering initiative and UN DESA. Accessed on 16 August 2021

Stoddard I, Anderson K, Capstick S, Carton W, Depledge J, Facer K, Gough C, Hache F, Hoolohan C, Hultman M, Hällström N (2021) Three decades of climate mitigation: why haven't we bent the global emissions curve? Annu Rev Environ Resour 46:653-689

Tosun J, Leininger J (2017) Governing the interlinkages between the sustainable development goals: approaches to attain policy integration. Glob Chall 1:1700036.

UNDESA (2016) Partnerships for the sustainable development goals. Support the SDGs through multi-stakeholder partnerships - ensuring that no one is left behind. Prepared by Division for Sustainable Development United Nations Department of Economics and Social Affairs. Available at https://sustainabledevelopment.un.org/ sdinaction/2016report

UNDESA (2019) High-level political forum 2019: voluntary national reviews synthesis report. Prepared by the United Nations Department of Economic and Social Affairs. Available online https:// sustainabledevelopment.un.org/vnrs/

UNEP (2014) GEO Small island developing states outlook. United Nations Environment Programme, Nairobi, Kenya. Available at http://www.unep.org/geo/sites/unep.org.geo/files/documents/geo_ sids_final.pdf

United Nations (2015) Transforming our world: the 2030 Agenda for sustainable development. Available at: https://www.un.org/ga/ search/view_doc.asp?symbol=A/RES/70/1=E

United Nations (2016). Global indicator framework for the sustainable development goals and targets of the 2030 agenda for sustainable development. Available online https://unstats.un.org/sdgs/. Accessed 10 March 2021

United Nations (2017) Our ocean, our future: call for action. Resolution adopted by the General Assembly on 6 July 2017, A/RES/71/312

United Nations (2019a) Political declaration of the SDG summit, gearing up for a decade of action and delivery of sustainable development. UN Doc. A/RES/74/4. United Nations, New York. Available from https://sustainabledevelopment.un.org/sdgsummit. Accessed 25 June, 2021
United Nations (2019b) United Nations sustainable development cooperation framework. United Nations, New York. Available from https://unsdg.un.org/resources/united-nations-sustainable-devel opment-cooperation-framework-guidance. Accessed 10 July 2021

United Nations (2020) Tier assessment for global indicators, updated as of April, 2020. Available at https://unstats.un.org/sdgs/

United Nations (2021) Our common agenda: report of the secretary general. United Nations, New York. Available from https://www.un.org/ en/content/common-agenda-report/. Accessed 12 September 2021

van Hille I, de Bakker FG, Ferguson JE, Groenewegen P (2020) Crosssector partnerships for sustainability: How mission-driven conveners drive change in national coffee platforms. Sustainability 12(7):2846

Van Soest HL, Van Vuuren DP, Hilaire J, Minx JC, Harmsen MJ, Krey V, Popp A, Riahi K, Luderer G (2019) Analysing interactions among sustainable development goals with integrated assessment models. Glob Transit 1:210-225

Van Tulder R, Seitanidi MM, Crane A, Brammer S (2016) Enhancing the impact of cross-sector partnerships. J Bus Ethics 135(1):1-17

Vinca (2020) Transboundary cooperation a potential route to sustainable development in the Indus basin. Nat Sustain. https://doi.org/ 10.1038/s41893-020-00654-7

Wagner P, Torney D (2020). Ireland's climate action plan 2019. A social network analysis of a policy implementation network. Policy brief. Available online

Weitz N, Nilsson M, Davis M (2014) A nexus approach to the post 2015 agenda: formulating integrated water, energy, and food SDGs. SAIS Rev Int Aff 34:37-50. https://doi.org/10.1353/sais

Weitz N, Carlsen H, Nilsson M, Skånberg K (2017) Towards systemic and contextual priority setting for implementing the 2030 agenda. Sustain Sci 13(2):531-548

Weitz N, Carlsen H, Nilsson M, Skånberg K (2018) Towards systemic and contextual priority setting for implementing the 2030 Agenda. Sustain Sci 13:531-548. https://doi.org/10.1007/ s11625-017-0470-0

Westman L, Broto VC (2018) Climate governance through partnerships: a review of 150 urban initiatives in China. Glob Environ Chang 50:212-221

Wichelns D (2017) The water-energy-food nexus: is the increasing attention warranted, from either a research or policy perspective? Environ Sci Policy 69:113-123. https://doi.org/10.1016/j.envsci. 2016.12.018

World Bank (2018) Operational Framework for Strengthening Human, Animal, and Environmental Public Health Systems at their Interface. International Bank for Reconstruction and Development/The World Bank, Washington DC

Xu J, Renaud FG, Barrett B (2021) Modelling land system evolution and dynamics of terrestrial carbon stocks in the Luanhe River Basin, China: a scenario analysis of trade-offs and synergies between sustainable development goals. Sustain Sci. https://doi. org/10.1007/s11625-021-01004-y

Zhou M, Moinuddin M (2017) Sustainable Development Goals interlinkages and network analysis: A practical tool for SDG integration and policy coherence. Institute for Global Environmental Strategies (IGES), Kanagawa, Japan

Zusman E, Amanuma N (2018) Governance for integrated solutions to sustainable development and climate change: from linking issues to aligning interests. Institute for global environmental strategies report. Available at https://iges.or.jp/en/pub/governance-integratedsolutionssust. Climate change mitigation potential. The IEA World Energy Outlook Special Report on Energy and Climate Change estimated methane emissions from oil and gas globally as, 76

Publisher's Note Springer Nature remains neutral with regard to jurisdictional claims in published maps and institutional affiliations. 